\title{
Sensemaking and the Chemtrail Conspiracy on the Internet: Insights from Believers and Ex-believers
}

\author{
SIJIA XIAO, University of California, Berkeley, United States \\ COYE CHESHIRE, University of California, Berkeley, United States \\ AMY BRUCKMAN, Georgia Institute of Technology, United States
}

How do people come to believe conspiracy theories, and what role does the internet play in this process as a socio-technical system? We explore these questions by examining online participants in the "chemtrails" conspiracy, the idea that visible condensation trails behind airliners are deliberately sprayed for nefarious purposes. We apply Weick's theory of sensemaking to examine the role of people's frames (beliefs and worldviews), as well as the socio-technical contexts (social interactions and technological affordances) for processing informational cues about the conspiracy. Through an analysis of in-depth interviews with thirteen believers and seven ex-believers, we find that many people become curious about chemtrails after consuming rich online media, and they later find welcoming online communities to support shared beliefs and worldviews. We discuss how the socio-technical context of the internet may inadvertently trap people in a perpetual state of ambiguity that becomes reinforced through a collective sensemaking process. In addition, we show how the conspiracy offers a way for believers to express their dissatisfaction with authority, enjoy a sense of community, and find some entertainment along the way. Finally, we discuss how people's frames and the various socio-technical contexts of the internet are important in the sensemaking of debunking evidence, and how such factors may function in the rejection of conspiratorial beliefs.

\section{CCS Concepts: • Human-centered computing $\rightarrow$ Empirical studies in collaborative and social com- puting.}

Additional Key Words and Phrases: social media, sensemaking, conspiracies, chemtrails, misinformation

ACM Reference Format:

Sijia Xiao, Coye Cheshire, and Amy Bruckman. 2021. Sensemaking and the Chemtrail Conspiracy on the Internet: Insights from Believers and Ex-believers. Proc. ACM Hum.-Comput. Interact. 5, CSCW2, Article 454 (October 2021), 28 pages. https://doi.org/10.1145/3479598

\section{INTRODUCTION}

Many people believe in conspiracy theories that are inconsistent with conventional views of reality - like the ideas that the earth is flat, the US government perpetrated the attacks against the United States in September 2001, and that US public health warnings and stay-at-home orders related to COVID-19 were part of a conspiracy [19, 29, 84]. In recent years, many conspiracy theories thrive on internet forums and websites $[4,81]$. Some of these conspiracies lead to dangerous actions by believers, causing great social and political harm to society $[5,64,82]$.

Authors' addresses: Sijia Xiao, University of California, Berkeley, South Hall, Berkeley, CA, 94720-4600, United States, xiaosijia@berkeley.edu; Coye Cheshire, University of California, Berkeley, 305A South Hall, Berkeley, CA, 94720-4600, United States, coye@berkeley.edu; Amy Bruckman, Georgia Institute of Technology, 85 5th St., TSRB 338, Atlanta, GA 30332-0760, United States, asb@cc.gatech.edu.

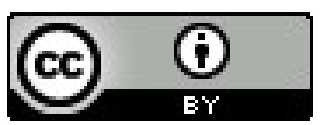

This work is licensed under a Creative Commons Attribution International 4.0 License.

(c) 2021 Copyright held by the owner/author(s).

2573-0142/2021/10-ART454. https://doi.org/10.1145/3479598

Proc. ACM Hum.-Comput. Interact., Vol. 5, No. CSCW2, Article 454. Publication date: October 2021. 
Conspiracy theories are claims that attempt, "to explain some event or practice by reference to the machinations of powerful people, who attempt to conceal their role" [82]. According to Samory and Mitra, a conspiracy theory usually involves a powerful agent that carries out some secret, covert actions on their targets [73]. As the definition shows, conspiracy theories often deal with incomplete, uncertain, changing, and uncorroborated data. Actively seeking and sharing information about conspiracy theories are arguably attempts to organize and comprehend the unknown. In all aspects of life, people "structure the unknown" through the process of sensemaking [88]. Previous research shows that the internet is now the major site where believers get and share information about conspiracy theories $[81,84]$. We aim to better understand how individuals use internet tools and systems for individual information-seeking and social interaction when they engage with a conspiracy theory about chemtrails. How do people come to believe (and stop believing) a conspiracy theory, and what role does the internet play as a socio-technical system in the sensemaking process?

We focus on the chemtrails conspiracy as a specific exemplar of a popular, widespread conspiracy with a significant internet presence. This conspiracy theory focuses on the belief that contrails (the visible condensation trails behind commercial airplane wings) are deliberately sprayed chemicals used for secret, nefarious purposes. Despite the lack of corroborated, factual evidence about the existence of chemtrails, a national poll in 2017 showed that $10 \%$ of Americans think the chemtrails conspiracy is "completely true," while $20-30 \%$ believe it is "somewhat true" [83]. There are a variety of theories regarding the purpose of chemtrails. Some of the most popular theories include the idea that chemtrails are for manipulating the weather, deliberate depopulation, or mind control (for a full review, see [9]). Some believers use the word "chemtrails" interchangeably with "geoengineering," which is an active scientific research field focusing on "intentional large-scale manipulation of the environment, particularly manipulation that is intended to reduce undesired anthropogenic climate change" [37].

When people try to solve numerous issues of ambiguity at the same time, they often engage in a process of collective sensemaking [89]. In our research, we examine how the socio-technical aspects of the internet are important for believers' collective sensemaking about the chemtrail conspiracy. We adopt Weick's sensemaking framework, which considers the frames, cues and context to explain how people make sense of uncertain information [89]. Weick defines frames as past moments of socialization, cues as present moments of experiences, and context as "local contingencies" where people make sense of cues. Thus, people understand cues (such as information about a conspiracy) in relation to their own frames (prior beliefs and worldviews), within a given context (time, place, and socio-cultural meaning).

Our first two research questions concern the sensemaking process of how believers adopt the conspiracy theory. We first examine how people relate different cues to their existing frames such as beliefs, ideologies and worldviews:

RQ1: How do beliefs and worldviews frame believers' perception about the chemtrail conspiracy theory?

Next, we examine how people receive and share informational cues about conspiracy theories in the context of internet interactions. We pay attention to both the social and the technical aspect of the online context, and how they collectively influence people's interpretation of conspiracy theories:

RQ2: How are the social and technical aspects of internet technologies and platforms important for believers' sensemaking about the chemtrail conspiracy theory?

Believers and ex-believers are both important for understanding the wide range of nuanced opinions and different theories that appear to support a specific conspiracy. However, ex-believers 
are also distinctive because they can help us to better understand how and why individuals shift away from these conspiracy beliefs. Previous research has shown that it is often very hard to persuade believers in conspiracy theories to change their minds once they adopt the beliefs [28] While much has been researched and discussed about ex-believers in religious groups and cults (e.g., $[77,90])$, very little research exists on how internet technologies, social interactions and beliefs and worldviews work in the sensemaking process of rejecting prior belief in a conspiracy theory. Thus, we also investigate a third research question concerning the sensemaking process of becoming an ex-believer:

RQ3: How are the internet technologies, social interactions, and beliefs and worldviews important for changing from believer to ex-believer in the chemtrail conspiracy theory?

Through in-depth interviews with 13 chemtrail conspiracy believers 7 ex-believers, we examined the specific ways that believers and ex-believers seek and make sense of the available online information about chemtrails. The chemtrail conspiracy, like other conspiracies, consists of incomplete and uncorroborated narratives and evidence. The internet becomes a primary site for believers' collective sensemaking process in order to deal with ambiguity regarding the conspiracy. We find that the narratives of the chemtrail conspiracy align with believers' frames (e.g., pre-existing beliefs and worldviews), and provide answers to their concerns about real-world issues. We show how believers' common frames, such as distrust of authority, combined with with the socio-technical context of the internet can result in a false sense that pro-chemtrail evidence is abundant. We discuss how believers adopt the chemtrail narratives because they perceive a massive amount of discussion and support in chemtrail online communities, even though they may not actually think that any final "proof" yet exists.

Our research also provides insights on the debunking of false conspiracy theories. By understanding the sensemaking process of believers and ex-believers, we find that presenting debunking information alone rarely works: one's beliefs and worldviews, online social interactions, and the technological affordances of the internet greatly limit exposure to debunking information. Furthermore, believers explain how they dismiss debunking information before close reading, and even turn debunking information into evidence in support of chemtrails. We suggest that combating false conspiracies and other forms of misinformation online requires concerted efforts to increase exposure to truthful counter-narratives using both technological (i.e., algorithmic recommendations) and social forces (i.e., encouraging productive discussions and debates outside of closed echo chambers). In particular, we suggest that a potentially fruitful approach is to nurture more social translucent platforms, while encouraging trust and understanding between different viewpoints before conveying counter-evidence.

Historically, the study of how interactive computing systems and the internet facilitate human sensemaking has been an important line of work in computer-supported cooperative work and human-computer interaction. In recent years, there has been increased interest in online sensemaking activities that involve, "active, iterative, interaction with massive amounts of information to distill it into forms that provide insight and support effective action" [63]. Our work adds to this line of research by examining how people make sense of online conspiracy theories in an internet landscape rife with massive amount of incomplete and often inconsistent information. By investigating the technologies and their social uses by individuals who believe (or used to believe) in a popular conspiracy theory, we aim to provide insights that can help us to be better informed about how and why conspiracies, misinformation, and even intentional disinformation can spread on the internet. 


\section{RELATED WORK}

\subsection{Conspiracy Theories on the Internet}

Conspiracy theories have been around in human history [84]. In recent years, the internet has become a primary location where conspiracy theories thrive $[4,81]$. But, what happens online does not necessarily stay online- sharing and participating in conspiratorial beliefs may lead to serious consequences in the offline world. The QAnon conspiracy originating from online forums such as 4chan is associated with multiple violent hate crimes and mistrust towards the US government $[2,27]$. In addition, those who primarily rely on social media for news about covid-19 are more likely to believe that the pandemic is planned and that vaccination is unnecessary [55]. The problems of how people spread and make sense of conspiracy theories online is now an active and growing area of research [36, 92].

One line of research examines the spread of conspiracy theories in specific online information networks. For example, Starbird found an alternative media ecosystem on Twitter that promotes conspiracy theories about mass shooting events as well as fanatical political beliefs [78]. Others examine the role of online discourse among conspiracy theorists. For example, Samory and Mitra conducted a series of studies to categorize the types of conspiratorial statements [73] and the types of users who consume conspiracy content on Reddit [72].

Another body of research attempts to understand how the internet provides socio-technical environments that are ripe for conspiratorial information sharing. Bessi et al. found that people form polarized communities around mainstream scientific and conspiracy news [6]. In addition, Mitra et al. and Phadke et al. examined how people's social characteristics (e,g, interaction with online conspiracy theorists, attitudes towards the government) relate to their conspiracy beliefs online [56,61]. Many researchers have examined how conspiracy theories emerge in the collective sensemaking process online after crisis events [42, 44, 79].

Other research applies a psychological or social psychological lens to the problem of conspiracy theories and their consequences. Some researchers examine the psychological and social factors that influence people's beliefs in conspiracy theories. Many researchers found that belief in conspiracy theories is largely influenced by people's predispositions based on their existing beliefs and attitudes, for example, distrust in authority $[10,16,56]$. In addition, research finds that belief in one conspiracy theory makes a person more likely to believe in another, and may eventually lead to a broader conspiratorial worldview [85].

Once beliefs about conspiracies are formed, they can be extremely hard to change [28]. Believers may reject corrective information, particularly when it threatens their existing worldview and selfconcept [14] or if it might limit their behavioral freedoms [49]. Researchers have examined different ways to correct false information and counter beliefs in conspiracy theories [33, 57]. Corrective processes include presenting evidence strategically [23] and applying storytelling techniques [76] In particular, researchers examined how online platforms can tackle the proliferation of conspiracies by implementing fact-checking, which refers to the assignment of "truthfulness" values by a third party, and/or additional evidence to confirm or refute online claims [12, 86, 92].

In recent years, fact-checking has become a common tool on many social media platforms (e.g., Google, Facebook and Youtube) [22, 43, 50]. For example, in videos about controversial conspiracy theories, YouTube attaches a link to the corresponding Wikipedia page. In addition, Facebook enables users to flag information they consider problematic or false, directs the information to third-party fact-checkers, and attaches an informational label to disputed information along with fact-checking articles. Walter et al. conducted a meta-analysis on 30 research studies about factchecking and found that in general, fact-checking has a positive effect on the correction of beliefs [87]. Researchers also examined the effectiveness of different types of fact-checking techniques.

Proc. ACM Hum.-Comput. Interact., Vol. 5, No. CSCW2, Article 454. Publication date: October 2021. 
Examples include the presentation of visual rating scales [3], fact-checking from other social media users [35], and automated fact-checking with machine learning algorithms [32]. Research also shows how personal traits such as preexisting beliefs, worldviews [28, 49] and political knowledge and beliefs [87] influence the effectiveness of fact-checking.

\subsection{Sensemaking}

Sensemaking is "a process in which individuals develop cognitive maps of their environment" [68]. According to Chater and Loewenstein, sensemaking is a strong human motivation: it is "the desire to make sense of our immediate experience, our life, and our world" [11]. The sensemaking process is made most salient when people notice something in the form of a surprise, or something that "does not fit" [89]. In the human-computer interaction and CSCW communities, sensemaking has been directly applied to diverse topics such as collaborative web search [60], idea generation with crowds [91], self-directed learning [7, 62], and other forms of knowledge creation [13, 63].

There are many theories of how people make sense of information, many of which include three core elements: a frame that constitutes people's past experiences, the context where informational cues are embedded, and the cues that we experience or observe [39, 58, 89]. According to Weick, sensemaking is the process of fitting informational cues into a frame, which is influenced by the context where cues are embedded [89]. In this paper, we contextualize our findings using Weick's sensemaking theory.

The concept of frame was originally proposed in Goffman's work, where he defines it as "a culturally relative system of rules, principles and so on, that are used to organize society and guide individual behavior" [31]. Klein et al. proposed that frame is a reflection of a person's compiled experiences [40]. Together, these experiences may assemble as a frame for a person's ideology, worldview, or perceived social norms [89].

Weick explains that context encompasses the "local contingencies" where people make sense of the information [89]. To him, the context may include the social environment and physical settings, such as the speaker that conveys the information, the settings in which the information is conveyed, and the relationship between the speaker and listener. In the online world, context would include the socially interactive environment as well as the technical infrastructure of online platforms. Context influences the information extracted from a situation, and how the information is interpreted $[34,58]$.

While people interpret informational cues within the frame and context, the cues also shape the context and frame in return. Klein et al. argue that the process of interpreting cues works to test, adapt and improve the frame [38]. Weick explains that action is crucial for sensemaking, because action will change and define the environment where a person makes sense: "there is not some kind of monolithic, singular, fixed environment that exists detached from and external to these people...they act, and in doing so create the materials that become the constraints and opportunities they face" [89].

According to Weick, the outcome of sensemaking is usually a narrative that can connect the information with the frame to form a coherent story [89]. Thus, the goal of sensemaking is to reach a functional understanding, which may lead people to choose a plausible narrative instead of pursuing accurate details. As a result, the sensemaking process tends to be forgiving - people may ignore the information that does not align with their existing frames and interpret the information and context in ways that align with their frames. Weick also believes that the tendency to suffice is particularly salient when people are facing limited data and uncertain environments. However, he argues that sensemaking of an event is an ongoing process that never stops. As a result, though people may reach a decision after a sensemaking process, there are opportunities for people to receive new 
Table 1. List of chemtrail believers and ex-believers

\begin{tabular}{lllllll}
\hline P\# $^{1}$ & Source $^{2}$ & Gender & Occupation & Age & Education & Location \\
\hline B1 & Reddit & Male & Quality inspector & 30 & Undisclosed & Belgium \\
B2 & Facebook & Male & Bicycle mechanic & 38 & Undisclosed & Netherlands \\
B3 & Twitter & Male & Audiovisual designer & 34 & High school & California \\
B4 & A chemtrail forum & Male & Office worker & 53 & Some college & Maine \\
B5 & Reddit & Male & Logistics analyst & $20-40$ & College & United States \\
B6 & Discord & Male & Painter & 39 & High school & Kansas \\
B7 & Reddit & Male & Telemarketer & 24 & Some college & Oklahoma \\
B8 & Discord & Male & Steel business & 48 & Some college & Canada \\
B9 & Discord & Male & General contractor & 32 & College & Washington state \\
B10 & Facebook & Female & Unemployed & 40 & College & Indiana \\
B11 & Discord & Male & Meat department & 33 & High school & Indiana \\
B12 & Reddit & Male & College student & $20-30$ & College & New York \\
B13 & Reddit & Male & Taxi driver & 32 & High school & England \\
E1 & Facebook & Male & Law enforcement & 28 & College & Florida \\
E2 & Facebook & Male & Musician & 47 & College & Washington state \\
E3 & Facebook & Male & Gardener & 48 & High school & England \\
E4 & Facebook & Female & Teacher & 50 & College & Florida \\
E5 & Facebook & Male & Automotive technician & 29 & Some college & Canada \\
E6 & Facebook & Female & Chef & 50 & Trade school & Canada \\
E7 & Facebook & Male & Property security & 55 & College & England \\
\hline
\end{tabular}

${ }^{1}$ Participant number. "B" refers to chemtrail believer, "E" refers to chemtrail ex-believer.

${ }^{2}$ The platform where we recruited participants. To protect the privacy of our participants, we identified the general platform where we recruited each participant, but not the specific group on any site.

information that reshapes their decisions. As Weick explains, "it makes good evolutionary sense to construct an organism that reacts significantly when the world is no longer the way it was."

\section{METHODS}

We use a qualitative design, consisting of in-depth interviews with those who participate in online groups related to the chemtrail conspiracy. We conducted 20 semi-structured interviews, including 13 with chemtrail believers and 7 with chemtrail ex-believers (see table 1). Thus, all interviewees in our study currently are, or were, believers in the chemtrail conspiracy. This study was approved by our Institutional Review Board (IRB). Participants were not compensated.

\subsection{Recruitment}

Our recruiting strategy was a combination of purposeful and snowball sampling, which involves non-random sampling of individuals where the processes and experiences of interest are most likely to be observed [70]. We recruited participants on multiple online conspiracy communities on Facebook, Reddit, Discord, etc. We identified chemtrail believers through their public posting histories and later confirmed their beliefs during the conversation. Believing in chemtrails or not is not a binary decision. Since conspiracy theories are mysterious by nature, many people may be unsure about certain elements of the chemtrail conspiracy theory (e.g., the conspirators, the chemical components of chemtrails, the process of spraying, etc.). People may also learn about different theories of chemtrails, and agree with all or only some of them. We consider respondents as believers when, for at least one theory, they tell us that it is true or lean toward the possibility that it is true.

We used the internal message system on each platform to contact potential participants. We established ourselves as researchers and expressed our interest in learning their views on chemtrails. 
We were truthful about our own standpoint. If people asked about our beliefs, we told them we do not believe in chemtrails, but have an open mind and would like to learn about their views. After we interviewed each participant, we asked if they would refer us to other believers ${ }^{1}$.

It was challenging to locate ex-believers through public posts to pro-chemtrail forums, as exbelievers were not likely to see our requests. After getting agreement from the moderators of several anti-conspiracy Facebook groups, we published recruiting posts in those groups to find people who once believed in chemtrails but no longer do. Some ex-believers voluntarily contacted us from these groups. In addition, anti-chemtrail activists from these groups directly referred us to specific ex-believers that they had helped to convert.

\subsection{Interview Procedure}

All interviews took place between August 2018 to January 2019. Eighteen interviews were conducted through video or voice calls, while two participants (B5, B12) chose to use the private chat of Reddit or Discord. The interviews lasted around 90 minutes. For all participants, we asked about their belief-changing trajectories starting from the time they first heard about chemtrails. For believers, we asked about their trajectories towards believing in chemtrails; for ex-believers, we first asked their trajectories towards believing, followed by their trajectories for exiting beliefs. In the process, we tackled the key evidence they found and their underlying rationale in changing their beliefs. We followed a semi-structured interview format in which we began with a rough list of questions, but then followed up on things participants said [75]. The beginning part of our interview emphasized questions about people's online influences. As participants built rapport with us, they also revealed how their personal life experiences shaped their beliefs. The researchers then expanded on those experiences and asked further questions.

\subsection{Data Analysis}

We transcribed the interview recordings and used Dedoose (https://www.dedoose.com/) to code the data. We applied interpretative qualitative coding to the data [54]. We began with initial coding, where we applied short phrases as codes [71]. The first round of coding was done on a line by line basis so that the codes stayed close to the data. Examples of first-level codes include "experienced local corruption" and "keep belief to self". Next, we conducted focused coding by identifying constantly occurring themes to form high-level descriptions [71]. Some second-level codes include "distrust of the government" and "online platform usage". For ex-believers, we analyze their experiences before exiting beliefs along with the experiences of current believers in our sample. The coding was done in an iterative process. The first author frequently reviewed the interview scripts and discussed emerging and evolving themes with the other authors.

After several rounds of initial and focused coding, we applied Weick's sensemaking framework to guide our interpretations [89]. We aligned the coding themes with the three key elements in Weick's framework: frames (beliefs and worldviews), context (online social interaction and technological affordances of the internet) and cues (information received and interpreted in these contexts).

\footnotetext{
${ }^{1}$ Many of our participants feel passionately about this subject, and they were eager to share their beliefs as openly and honestly as possible for this research. In an unexpected twist, we were contacted by a staff member at our transcription service who identifies as a chemtrail believer. They told us that they could get fired for contacting us, but they really wanted to share information about chemtrails with us because this topic is so important. We reported this to our human subjects office, and did not contact them further since we did not want to reward the violation of confidentiality. Based on advice from the human subjects office, we chose not to inform their employer. This incident is an indication of just how important this topic is to some people, and the challenge of openly discussing such beliefs which are popularly considered unfounded conspiracies.
} 
Finally, we established, interpreted, and organized the connections between the sensemaking framework and the coding themes to arrive at our findings.

\subsection{Methodological Limitations}

We used convenience and snowball sampling to recruit participants, and recruited on several major social media platforms. Thus, our sample may not be representative of all online interactions and discussions related to chemtrails. We asked our interviewees to reflect back on their belief change process, and it can be hard for people to accurately recall how their beliefs changed over time.

We rely on self-identified believers and ex-believers, so we are not able to reach the people who do not wish to reveal their beliefs about chemtrails. In addition, our sample did not include any "conspiracy trolls"- people who do not actually believe, but pretend to believe in online discussion groups [29]. Finally, we did not interview any chemtrail activists who asked for donations from followers to support their research on chemtrails or sell products related to chemtrails.

\subsection{A Note on Epistemology}

It is important to note that conspiracy theories differ in a variety of important ways. First, while many conspiracy theories are demonstrably false, some conspiracies turn out to be true. Second, some conspiracy theories incorporate radicalized, anti-normative beliefs and actions that are "in violation of important social norms" [46], yet many other conspiracies involve a search for truth without radicalized beliefs or the radicalization of believers. For the purposes of this research, how do we establish what is or is not true regarding conspiracy theories?

In this work, we build on a "pragmatic realist" notion of reality: the world exists, but is only knowable by our fallible senses [47]. Additionally, we rely on the idea of the social construction of knowledge [48]. What most people agree is true at any given moment in time is our best available attempt at knowledge, and may later be revised based on new information. Within this framework, each currently popular conspiracy theory could be assigned a probability of being true. We have chosen chemtrails as a conspiracy which we think is highly unlikely to be deemed true by any established scientific perspective. Ultimately, questions about how people make sense about what to believe are of scholarly interest regardless of the verifiable truth of the underlying ideas.

\section{MAKING SENSE OF CHEMTRAILS: FRAMING BELIEFS AND WORLDVIEWS}

Our first research question concerns the role of beliefs and worldviews in framing beliefs about the chemtrail conspiracy theory. In Weick's sensemaking theory, people understand and interpret information with frames, which consist of their beliefs and worldviews shaped by their lived experiences [89]. We found that many believers describe common frames that influence their sensemaking about the chemtrail conspiracy. The chemtrail conspiracy consists of a detailed narrative that provides answers to people's concerns about real-world issues. In the section, we detail the life experiences, beliefs, and worldviews that believers described before they came across the chemtrail conspiracy, and how those factors influence their sensemaking process.

\subsection{Health and the Pollution}

Several participants related chemtrails to their health problems or their concerns about pollution. Some participants (B4, B10) indicated that they blamed chemtrails as the reason for their health problem. At the time of our interviews, these individuals were suffering from a number of health problems. They believed those problems were unusual so they were looking for a possible cause. B4 searched on the internet and found many people with similar symptoms who pointed to chemtrails as the cause. He thus took notice of the condensation trails in the sky, and found what he believed was a direct relationship between chemtrails and his symptoms. 
"I saw these trails and then about 30 minutes or so later there was the taste of metal. It was actually a salty metallic taste, really, really strong. Immediately I got a bad headache, my muscles and joints started hurting." (B4)

B10 told us that at one time she almost did not survive her ongoing illness. Besides, she has experienced many deaths around her: "Why are my friends all dead from cancer? Why is my mother dead at 60? Why?" During a particularly difficult period, she heard about chemtrails on a conspiracy television series and adopted it as the "real cause" of her diseases.

Some chemtrail believers were concerned about the environment and motivated to stop related environmental problems. The chemtrail narratives usually describe chemtrails as a form of harmful substance used for nefarious purposes, thus these individuals think of chemtrails as an extended form of pollution:

"Chemtrails are probably the largest single source of pollution in the world today that they will legitimize in the public eye...We're having animal die-offs and plant die-offs and insect die-offs, rising free aluminum levels in the soil...you would expect when you see these types of substances in the atmosphere. "(B4)

Reflecting back on his beliefs, E5 expressed that he was convinced of chemtrails in the beginning because of the evidence linking them to important environmental issues. He was anti-GMO (genetically modified organism) at that time, and a Youtube video he watched connected GMOs to the chemtrail conspiracy. E5 explained how the connection to large and powerful GMO companies such as Monsanto can convince some people to believe:

"If they [people who watch the video] hear something like that that Monsanto's behind it as well, they're more likely to believe it because it's something they're familiar with. It's not just some crazy idea that 'Oh, they're spraying stuff in the sky."'

\subsection{Distrust of Authority}

Many of the broader beliefs and worldviews that we heard about from believers tend to be related to the idea that the world or the country they belong to is operated under secret, powerful, and untrustworthy authorities. For these individuals, the chemtrail conspiracy becomes a piece of supporting evidence for their larger concerns about knowledge and power in society. Importantly, we find that believers' distrust towards authority often comes from their past experiences.

Believers' distrust of the government comes from multiple sources, including their family members' distrust of the government (B6, B10, E6), their disagreement with how the government handles war (B3, B4, B10), or the perceived corruption they see in the government (B9, B6, B11). B10 described how her family suffered during the Vietnam War, and how it affected her beliefs about how the government uses chemicals:

"Daddy was a Vietnam veteran...and dad got fed Agent Orange. Thankfully, to our government, they said, 'Oh, well we know we poisoned you. It's all good. You fought a battle for us...and we're going to go ahead and let you die. Oh, and by the way, your kids are going to be affected too.' See, I've been sick for a long time. In 2007 I almost died." (B10)

B9, B6 and B11 claimed that they have witnessed corruption and dysfunction in their local government. Furthermore, believers in our study frequently referred to the corruption and dysfunction of the government from history:

"There's an example from the Dugway Proving Grounds...they [the government] were testing this over populated areas, where people could've got hurt. And to me, that just shows a negligence from the American government, kind of thing, involving aerosol sprayed from planes." (B7) 
We found that believers tend to have a general distrust of authority and people with power, but in our sample, they did not relate the distrust to a particular political party affiliation. The participants had diverse political beliefs, including three libertarians, three centrists, two conservatives and eight believers who do not claim to hold any specific political beliefs. Across our interviewees, it was common to hear that it is the political system that is problematic instead of any particular political party:

\section{"There's no difference between the Democrats and the Republicans, it's just different sides of the same coin." (B11)}

Some believers extend their distrust of the authority to the mainstream media since they believe the media is coerced by people in power:

"It's proven that the news is owned by larger companies...so if anything comes up in the news, it must mean that someone said, 'Okay, run this story. Spin it this way.”' (B3)

We find that the distrust of mainstream media makes many of the believers abandon mainstream media as a source of information. These believers describe how they turn to social media sites and online communities outside of the perceived mainstream that better align with their beliefs. Believers appreciate the freedom of information sharing provided by social media platforms, where they are able to discuss topics that are not covered by mainstream news organizations:

"They [the conspiracy podcasts] will talk about facts that aren't really talked about in the mainstream." (B6)

However, some believers also think they are gradually losing their freedom to discuss topics avoided by mainstream news sources on social media. Many believers expressed their distrust about those online users who share counter-evidence related to the chemtrail conspiracy. Some told us that people who debunk conspiracy theories are "shills," or untrustworthy government agents who spread anti-conspiracy information as a cover-up. They thus further narrow down their social media choice by abandoning social media or online communities where they frequently encounter opposing views. For example, B12 talked about how he abandoned Instagram: "I deleted Instagram...you're not gonna get real facts given to you. That's like watching TV and expecting to get 'news' without a biased view."

\subsection{Beliefs in Multiple Conspiracy Theories and Conspiratorial Worldview}

Beliefs in multiple conspiracies was common among our respondents, as the broader narratives about chemtrails and other conspiracies are often interrelated. One prominent example involves HAARP (High frequency active auroral research program), an ionospheric research program led by the U.S. Air Force [15]. Many chemtrail believers believe that HAARP is itself a conspiracy for the government to control the weather, and it is therefore linked to chemtrails for this purpose. One ex-believer explained how belief in one conspiracy can lead to beliefs in other conspiracies that share the same types of evidence:

"Like in the chemtrails and they're using it to poison us or make us sick...So if you think that vaccines are a conspiracy then that's not too far from that." (E2)

Interconnected beliefs about the government as well as the beliefs in other conspiracies could lead to a wider conspiratorial worldview, where people think that the world is operated under a secret powerful authority that acts for malicious purposes different from what mainstream media reports. Believers' pre-existing conspiratorial beliefs and worldviews may allow them to adopt new conspiracies theories more easily, especially when the new conspiracies are based on similar narratives or evidence as those they already believe. B11 said, "I've had a feeling that things are off for so long, and some of these conspiracies seem to help draw the lines together, connect the dots." It

Proc. ACM Hum.-Comput. Interact., Vol. 5, No. CSCW2, Article 454. Publication date: October 2021. 
also helps believers adopt new conspiracy theories more easily without much evidence. E6 reflected that when she first became aware of chemtrails, her existing conspiratorial worldview gave her an inclination to believe in the conspiracy theory: "It didn't take much to convince me. I didn't need loads and loads of proof."

\subsection{Religious Beliefs}

Religion can also be an important frame in one's overall worldview and perspective on science, knowledge and meaning. We found that religious beliefs influenced some of our respondents' broader beliefs about the world and the role of authorities in important ways. For example, B4 is a Christian and a believer of chemtrails. He uses words in the Bible as proof of chemtrails:

"There's a prophecy in Revelation 18:23...it says the powerful merchants of the earth receive the nations by their sorcery...the word 'sorcery' actually comes from the Greek word 'pharmakeía' which means to drug or poison. Shortly before the return of Christ...We're going through a great poisoning of the population that makes them fatigued, tired, lowers their IQ." (B4)

B6 and E2 once had religious beliefs, but told us that they abandoned these views before they became chemtrail believers. Crucially, they each explained that religion changed the way they think about the world. B6 traced his basic distrust of authority to a reaction to being taught what he believed to be falsehoods as part of a religious upbringing. Reflecting on his own experience as a chemtrail believer, E2 described how religion can act as a catalyst for people's sensemaking:

"Religious belief makes it easier for you to believe the story about these powerful people that they control everything and they're hiding all the information...but they [conspiracy believers] don't realize that they're caught in another mental trap that is actually not too far off from the religious beliefs. It's not based on evidence. It's all based upon faith." (E2)

\section{CONTEXT AND CUES IN TECHNOLOGIES AND SOCIAL INTERACTIONS}

Our second research question concerns the importance of socio-technical aspects of internet technologies in the sensemaking of chemtrails. Weick explains that when people interpret informational cues, it is important to understand the context where the cues are embedded [89]. In this section, we show how the internet provides both a technical and social context for observing, sharing, discussing, and evaluating information. Importantly, we first draw out the technical and social aspects sequentially, in order to facilitate our discussion of how the social and technical issues are inextricably intertwined in the sensemaking process. We also present some types of informational cues that are particularly convincing or attractive to believers.

\subsection{Technological Affordances of the Internet}

The internet is the major site where believers find information about chemtrails and make sense of it. We find that the internet is a great amplifier of believers' existing beliefs as it facilitates participants to personalize their experiences: it provides great agency for believers to locate and customize the information they receive. For believers who have a pro-conspiracy frame, or show interest in conspiracy theory, those personalization mechanisms can drag them into the rabbit hole of supporting information. Besides, the internet allows multiple media formats, some of which are particularly attractive and convincing for the believers (e.g., the photos or videos of condensation trails on the sky). The internet also grants people the mobility to move and share information across multiple platforms. Those mechanisms concentrate large amounts of conspiracy-related information and believers in conspiracy communities, and the amounts of people and information further become their cues for believing in chemtrails. In the section, we detailed how technological 
affordances of the internet provides the context where people explore chemtrails, and how people make sense of the information cues they find on the internet.

5.1.1 Agency to explore information: search. When participants look for information about chemtrails, they report frequently using search engines and the search function on various social media platforms. Such tools provide them agency in locating and selecting information they expect or want to see. B1 first encountered the conspiracy through a Youtube video. To find more information about it, he immediately conducted a google search: "I just googled it and I clicked on the first two or three results." The information he located was in support of the conspiracy:

"One site was [about] heavy metals in the sky to make global warming faster. And the other site was weird stories about, that they produce them [chemtrails] to make people sick." (B1)

Believers explained that they believe that search enables them to accurately and conveniently locate the information they need. B10 said, "If you plug it into Google, you can get that [information about chemtrails] easy." For some believers, not all information they locate are in support of chemtrails. However, believers explained how they learned how to manipulate search terms to get related results that tend to support chemtrails. E7 admitted that he tried and selected certain keywords to get search results that favor his views: "I didn't input chemtrails, because if I put that into Google, it becomes quite derogatory...I'd [instead] search for aerosol injection or solar radiation management."

5.1.2 Reinforcing design: recommendation algorithms and subscriptions. When using common search engines as well as social media platforms, believers receive additional content about chemtrails through recommendation algorithms. Several believers first encounter the chemtrail conspiracy because of a Youtube video recommended to them. B1 reflected on this process while discussing how he first learned about chemtrails: "You know, you can lose your way on YouTube. And then I saw something like chemtrails and checked it out." Believers also indicated that they keep receiving recommendations of conspiracy theories during their exploration process. Some believers are aware that they continuously receive information about chemtrails because of recommendation algorithms:

"I think those platforms are designed to, like, build around your interests, right. So when you start searching stuff by clicking on stuff they put more and more of that type of thing in your feed." (B9)

While believers describe the recommendation of conspiracy videos in a general, descriptive or neutral way, we also found that ex-believers place some blame on recommendation algorithms for helping to promote conspiracy related content. For example, one ex-believer (E1) told us, "Unless you typed in the word 'debunked,' it [debunking information] would not show up in your search results." Another ex-believer explained how he believes that recommendation systems make it difficult to even find legitimate counter-narratives:

"You'll see a thousand videos saying chemtrails are real before you run across more scientific information...the stuff that's more popular and gets the most engagement and comments and stuff, kind of goes to the top of the search engine." (E2)

In addition to recommendation algorithms, believers's subscriptions to pro-conspiracy media channels may also lead to streams of pro-conspiracy informational cues. Believers explained how they subscribe to multiple media channels such as podcasts, YouTube channels, and Facebook groups to learn about chemtrails. After subscribing to a media channel, believers passively encounter more frequent information about chemtrails. B11 admitted that he was not interested in exploring 
chemtrails voluntarily, but he still receives information about it through a podcast and its associated Discord discussion group.

5.1.3 Attractive media forms: official documents, images and videos. Participants frequently mentioned three forms of media that provide essential informational cues about the chemtrail conspiracy: images, videos, and government documents/patents. Believers explained that these are among the most convincing types of evidence that proves the existence of chemtrails.

Photographs of condensation trails in the sky are among the most common forms of informational cues that believers cite in their search for evidence and proof of the conspiracy. There are multiple theories of the chemtrails conspiracy, but all of them begin with the long-lasting condensation trails in the sky. With the agency to post information on the internet, many believers said that they shared pictures or videos of the condensation trail on the sky (sometimes with a flying plane) in conspiracy groups. E5 reflected that he used to post pictures of the sky on Facebook, "There were a couple pictures that I had taken of the sky...I was frustrated...It was such a nice clear sky, a nice sunny day and then there's these [chemtrails]." Some believers want to know why the condensation trails don't disappear immediately but instead last in the sky, so they use the picture as a way of inquiry. B1 posted a video of condensation trails on Reddit without any explanation or comment to "see what other people would comment." There are also believers who think that long-lasting condensation trails are the solid proofs of the conspiracy. As B12 commented, "Chemtrails have been the most interesting [conspiracy], because it's right in front of our face and we still choose to ignore it."

Online videos about chemtrails were also among the most frequently mentioned sources of engaging content and informational cues about chemtrails on the Internet. The videos believers cite and share is a form of evidence collages [45] that aggregates diverse supporting information including pictures and videos of condensation trails, statements from whistleblowers and selfdescribed chemtrail experts. B13 explained that, while there are other forms of documentation and media, it is most convenient to consume packaged information through videos: "[It] is very easy to go and have a look at someone's video...All the information, they've bundled it together, sugar coated it, and made it a really nice and fluffy package."

In their reflections, ex-believers pointed out that watching videos is a passive way of accepting information. E3 said, "[Watching conspiracy video] is a lazy man's way of educating yourselves. We just sit there and we listen to somebody else telling us something." E1 thinks that video content is designed to be manipulative and thus convincing: "It's just the appeal of the media. It looks good, it must be true." In addition, one ex-believer described how videos are effective because they are surprising and even disturbing:

"I think the best way to break through to someone and to grab their attention is to shock them. To pray on their emotions and fear and stuff like that." (E5)

Despite the aforementioned distrust of authority, believers referred to official documents on government websites, patents or research on geoengineering as strong proof of chemtrails. These believers explained that such documents show that the authority has the ability to spray chemtrails, or the tools for spraying chemtrails exist. With the agency to search on the internet and the wide availability of government document and patents, believers collect them and use them as proof:

"You can check with your local government. All you have to do is see what the United Nations are doing. If you look under sustainable development, then you can look at weather modification. If anyone tries to refute weather modification, all you have to do is look up, you can go to where they have patents for weather modification. That proves the tools exist." (B10) 
Table 2. List of internet services and tools participants used to explore the chemtrail conspiracy

\begin{tabular}{|c|c|c|c|c|c|c|c|c|}
\hline & Youtube & Google Search & Facebook & Official $^{1}$ & Discord & Reddit & Email & Twitter \\
\hline B1 & $x$ & $x$ & & & & $x$ & & \\
\hline B2 & $x$ & $x$ & $x$ & $x$ & & & & \\
\hline B3 & $x$ & $x$ & & $x$ & $x$ & & & $x$ \\
\hline B4 & $x$ & & $x$ & & & & $x$ & \\
\hline B5 & & & & $x$ & & $x$ & & \\
\hline B6 & $x$ & & & & $x$ & & & \\
\hline B7 & & & & & & $x$ & & \\
\hline B8 & & & & $x$ & $x$ & & $x$ & $x$ \\
\hline B9 & & $x$ & $x$ & $x$ & $x$ & & & \\
\hline B10 & $x$ & $x$ & $x$ & $x$ & & & $x$ & $x$ \\
\hline B11 & $x$ & & & $x$ & $x$ & & & \\
\hline B12 & $x$ & & & $x$ & & $x$ & & \\
\hline B13 & $x$ & $x$ & & $x$ & & $x$ & & \\
\hline E1 & $x$ & & & & & & & \\
\hline E2 & $x$ & $x$ & & & & & & \\
\hline E3 & $x$ & $x$ & $x$ & & & & & \\
\hline E4 & $x$ & & $x$ & & & & & \\
\hline E5 & $x$ & & $x$ & & & & & \\
\hline E6 & $x$ & $x$ & $x$ & & $x$ & & & \\
\hline E7 & $x$ & $x$ & $x$ & & & & $x$ & \\
\hline
\end{tabular}

${ }^{1}$ Government websites and patents.

5.1.4 Repetitive informational cues: cross platform and community sharing. Believers find, share and receive information across multiple online platforms and communities. For example, B2 is a moderator of three chemtrail Facebook groups and he talked about how he selected information to post in the groups: "[I select from] about 20 to 30 YouTube videos... and about 40 to 80 messages on Facebook." Given the importance of online platforms for learning about and discussing chemtrails, we asked participants to list the internet services and tools through which they seek information, share their beliefs of chemtrails and interact with other users. For descriptive context, Table 2 shows the platforms that participants said that they used frequently to learn about, share or discuss chemtrails. We do not list the specific names of the online communities to protect participants' privacy.

According to one ex-believer, the same information may be shared numerous times across the platforms and communities, thus could be repetitive. E7 reflected, "when I was involved, we were talking about the same things all the time, all the time, all the time. Really getting nowhere." Furthermore, some participants specifically described how chemtrail conspiracies are convincing, in part, because of the quantity of chemtrail information and the number of believers they see on various platforms. Other participants think that the chemtrail information they keep receiving makes them keep pay attention and inquire about the conspiracy.

"When something like this catches this much momentum in multiple communities across the world, it's not really localized to a few regions...That makes me lean more in the direction that this could be very plausible." (B3)

"I don't believe everything you read in a meme but...more information makes you curious, makes you research other places." (B9) 


\subsection{Social Interaction on the Internet}

Social interaction is another important way that informational cues are shared and interpreted in the chemtrail conspiracy. In a social-psychological view, people's thought, feelings and behaviors are influenced by the "actual, imagined, or implied presence of others" [1]. Weick argues that sensemaking is inherently social and retrospective: people make sense by thinking back on their past, social experiences and discussions with others [89]. In Weick's words, "people who study sensemaking pay a lot of attention to talk, discourse and conversation because that is how a great deal of social contact is mediated" [89]. As we describe below, the internet clearly makes it easy for people to locate and build connections with others who share similar beliefs, but it also turns sensemaking about the conspiracy theory into a deeply social, collective process. We find that believers moderate content and mobilize information all across the web, creating curated echo chambers [17] where only pro-conspiracy content is allowed and reinforced. In addition, we show that social approval, group problem-solving, and fun aspects of the community can further encourage exposure to conspiracy narratives.

5.2.1 Sharing through trusted relationships and alienation from non-believers. Some believers explained that they first learned information about chemtrails through close ties, such as their local relatives, friends or partners. Since they learned the idea from people they trust or respect, they found the arguments and evidence particularly convincing. For example, E5 learned about chemtrails from his father. He reflected, "I just kind of took his word for it, 'cause you know, he's my father, and I do respect most of what he says."

Of course, not all exposure to conspiracies comes from close relationships. The internet enables believers to connect with other believers around the world, and outside of their local ties and acquaintances. The internet tools and platforms help believers build relationships, learn about and process chemtrail information collectively. Believers described how they develop trust towards people who share similar views on chemtrails, and sometimes alienate themselves from people who hold different opinions. This can create a reinforcing social context where they only receive and discuss pro-chemtrail information.

Believers explained that they like to learn information from people who are trustworthy and approachable. For some, this may take the form of more formal online presentations and talks from "experts" in chemtrails. For others, this may take the form of relatable online personalities regardless of expertise. For example, B6 explained why he likes a particular conspiracy podcast:

"It was just two guys talking about things they've read... and that appealed to me, that it seemed like guys I knew sitting in a room talking about a subject, and not really pushing an agenda." (B6)

Our respondents often explained how they rely on a consistent group of people to acquire new information and to help form a sharing network of like-minded others. For example, B2 described how he mainly selects information to post from chemtrail activists he already knows: "I'm convinced they [chemtrail activists] are good at doing investigation." Similarly, another believer explained how he chooses information to share:

"There's... a consistent group of people who will send me private messages with articles that they feel are important, and then I'll select ones from there that seem to be credible and helpful for our cause and I'll post those." (B4)

While there are believers who openly share or evangelize their beliefs, others explained that they do not readily discuss their beliefs about chemtrails with non-believers. B5 explained that he knows the truth but he doesn't want to waste time convincing others. Some believers are aware that other 
people may judge their beliefs. For example, an ex-believer reflected about how he refrained from talking about chemtrails after negative reactions from his friends:

"It'd be a normal conversation about work...and I'd bring up the chemtrail stuff, and it would immediately, like crickets. Silence. And it's really embarrassing." (E7)

As we discussed earlier, some believers think that people who try to debunk chemtrails are "shills" who are (or are hired by) government agents to cover the conspiracy. Thus they are quite defensive to people who try to debunk, and avoid information that is anti-chemtrails. E1 reflected, "I'd post my own comments, respond to [debunkers], 'no you government shill this is real."'

5.2.2 Refining informational cues: content moderation. Many of the public social interactions between believers happen in moderated online platforms or systems. In these environments, the volunteer moderators or administrators decide what conversations, discussion, or content is considered appropriate for that particular forum, channel, or other online venue. Moderators or regulators are always chemtrails believers, thus the content others see in the chemtrail communities reflects the moderators' beliefs about what is relevant or not regarding chemtrails. As with any controversial topic, of course, the diversity of opinions varies. B6 moderates a Discord group and he believes that no one has a definite answer to conspiracies: "Nobody knows anything for certain, and it's okay to have your opinion, but show me proof before you go saying, "This is fact.",

Some online forums have particularly strong restrictions on topics and content. B4 is an administrator of a pro-chemtrail Facebook group and he has listed out internal rules for the six moderators to select content. Anti-chemtrail information is "the very top thing" (B4) that the group does not allow; furthermore, he detailed the chemtrail theories that are acceptable or not acceptable. B4 explained the rationale behind choosing chemtrail theories: "It's about including the largest number of people and educating them without going into subjects that are so far out that it would turn off the public." For example, in his group it is acceptable to say that chemtrails are for the purpose of weather control or depopulation, but it is not acceptable to state that chemtrails are used to re-engineer the atmosphere for aliens.

In addition to self-organized moderation, some large online platforms also have commercial content moderators to regulate content [69]. None of our respondents experienced explicit deletions or bans from online platforms for sharing pro-chemtrail content, though some ex-believers in our study blame online platforms for insufficient moderation of conspiracy related information. In particular, there exists a kind of assumed legitimacy for content that is not removed from the platform, even if the content is not verified or substantiated with further evidence. As one ex-believer explains:

"Anybody can upload a video on YouTube proposing some sort of idea of claim and if it's believable...they might not have any sort of credentials to be making these claims 'cause it's just a free platform that anyone can use." (E5)

5.2.3 Social incentives to participate: uniqueness, social approval and entertainment. In the pursuit of making sense of information and rationalizing their beliefs, the social context of conspiracy communities can provide believers with a sense of uniqueness, social approval and entertainment. These social incentives to participate are important because they attract and retain believers, who are then further exposed to conspiracy narratives and information.

Believers expressed that understanding conspiracies made them feel unique in the world. The chemtrail conspiracy, similar to other conspiracies, includes mysteries and secrets such as hidden evidence, alternate explanations from official stories, and other types of insider knowledge that is only known by believers. Respondents expressed how this kind of unique, special knowledge attract them to explore the conspiracy. B2 thought of himself as a targeted individual who was 
chosen for this special knowledge: "I think somebody is pulling on the strings. Somebody wanted me to go this way, into geoengineering, chemtrails and other so-called conspiracies." An ex-believer reflected that the sense of uniqueness was a strong incentive for her to participate in the conspiracy community:

"I grew up believing that I knew things that other people didn't know, which is what all conspiracy theorists believe... [that] they're in this little club of very lucky people." (E6)

Online conspiracy communities can provide a sense of social belonging with like-minded others, especially since many of the discussions are not part of mainstream knowledge or beliefs. In fact, many of the believers in our study indicated that they receive disapproval from their family or friends. As a result, the online conspiracy community is one of the only places where believers talk about and find acceptance for their shared beliefs about chemtrails. In addition, we find that believers may first come together because of their common interest in conspiracy theories, but then gradually develop friendships through broader topics. According to B3, he and other believers in a conspiracy community on Discord share advice for work and business, play online games together, and sometimes meet offline to "drink whisky and booze and play poker all night." The fact that many believers share broader interest can deepen their sense of connectedness and solidarity with one another, and make them stay in the conspiracy communities:

"I care pretty deeply for some of these people, because I sympathize with the way they live their lives and what they think...It's a support community. It's good vibes." (B6)

Finally, people may enjoy exploration of conspiracies, including chemtrails, in part because participation feeds their natural curiosity and they find it entertaining and fun. For some, the conspiracy can be exhausting if they feel that the answers they seek are never fully realized. Despite some of these frustrations, the "fun" of the conspiracy itself and keeping up with the community is itself a form of entertainment:

\section{"It gets tiresome because the answers never really come. But I don't know, I'd say it's more}

a source of entertainment than anything at this point for me personally." (B6)

For others, they explained how they enjoy exploring the various ideas, even if they have not fully adopted any conspiracy theories:

"Honestly, I don't actually believe any conspiracy theories 100\%, it's more just I like, I look at it as a form of media, or just a form of entertainment." (B11)

The social incentives to feel unique, receive approval from others, and find fun in the social exploration of the conspiracy are important for keeping individuals engaged with the chemtrail narratives. Though some individuals start with only mild curiosity and a sense of fun, they eventually become exposed to more convincing conspiratorial narratives. One believer described how he was initially pursuing his own interests and curiosity about geoengineering after reading an article in National Geographic magazine. He then told us that he found it fun to help organize and coordinate inside the communities. His ongoing exposure to the conspiracy communities eventually led to his adoption of related conspiratorial narratives about the chemtrail conspiracy:

"There were so many groups on Facebook, who were basically saying that it was nothing to do with climate engineering [geoengineering]...but it was purely a program which was linked to Agenda 21 [a chemtrail related conspiracy]...the more I read about this, the more I was inclined [to believe] their narrative." (E7)

\section{BREAKING BELIEFS}

Our third and final research question examines how the sensemaking process is important for changing one's beliefs and choosing to abandon the conspiracy. In this section, we discuss the 
challenges to belief that ex-believers describe in their sensemaking process about the chemtrail conspiracy. Across our interviews, there is no dominant reason that individuals choose to exit the conspiracy. However, we find that aspects of one's worldviews, beliefs, as well as the socio-technical context of online conspiracy groups can each play important roles in the process of exiting beliefs.

\subsection{Cracks in the Frame: Challenges to Beliefs and Worldviews}

When a concept such as chemtrails aligns with people's pre-existing beliefs or worldviews, they may understandably lean towards believing it regardless of the evidence. However, when some believers learn more about the fundamental aspects of the conspiracy, the narratives can also challenge their pre-existing beliefs or worldviews. For example, E5 reflected that he was at first convinced of the theory of chemtrails when he heard that they were used to combat climate change. However, he became skeptical of chemtrails when he heard claims that, in his estimation, were too far fetched: "[From the climate change theory] then it goes, everything from like a kind of a mass genocide or sterilization of the population." This same individual also mentioned how those different conspiracy narratives contradict one another: "They [the contradicting ideas] can't all be true...There's not a lot of evidence being presented to lead you one way or another, so that really made me question what I was believing in." He then started to reach out to debunkers himself and searched on the internet to find counter-narratives, and ultimately he changed his beliefs about the conspiracy.

When there are changes in one's worldviews or broader beliefs, it may also challenge the way they frame and understand conspiratorial beliefs. For E1, his change in religious belief was directly related to his change in beliefs about conspiracies. During college, he researched the history of his religious beliefs and became skeptical of specific claims: "Once I realized my religious beliefs regarding church history weren't true I started to question everything else." His change in religious beliefs therefore became a starting point of his skepticism of conspiratorial beliefs. He told us that he was finally converted to non-conspiratorial beliefs after a college professor persuasively debunked a conspiracy he once believed.

Earlier, we discussed how belief in one conspiracy theory may result in a wider conspiratorial worldview. This also can create inroads for challenging one's framing of conspiracies: when one conspiracy theory is debunked, it may result in the collapse of a whole series of conspiracies. All exbelievers we interviewed started to question other conspiracies they believed after they dismissed one conspiracy. For some of these individuals, chemtrails were the first to be debunked; for others, a different conspiracy was debunked but led to reconsiderations about chemtrails. Some ex-believers told us that once they dismissed the first conspiracy, they started to search for counter-narratives of conspiracy theories on the internet. This act of actively seeking debunking information quickly led them to confront inconsistencies in the conspiracies they once believed. As one ex-believer described:

"It would be as simple as googling 'conspiracy debunked'...and once I got to 70 out of the 100 conspiracy theories I believed in, I pretty much gave up, saying, 'okay, I'm not even gonna bother researching the other ones, they're probably bullshit too.”' (E1)

\subsection{Questioning Cues: Socio-technical Context of the Internet}

In prior sections we discussed how the design of internet platforms and systems can encourage the formation of echo chambers, where believers share beliefs only in a trusted network and are largely alienated from the views of non-believers. Additionally, believers tend to receive pro-conspiracy information because of recommendation algorithms and media subscriptions, and they rarely come across anti-conspiracy information due to heavy moderation of content. As we detail below, the catalyst for breaking beliefs is exposure to anti-conspiracy information, but the social context in 
which this information is presented is equally important. Ex-believers explained the importance of believability, tone, and social relationships with those who provide counter-narratives. In addition, the declining value of social interaction and other forms of entertainment also contribute to attrition from online conspiracy groups.

We found evidence that some particularly attractive debunking videos help believers question or even alter their beliefs. E6 used to dismiss "chemtrail debunking" content, but she accidentally clicked a video that she thought at first was pro-chemtrail but was actually anti-chemtrail. E6 explained that the video was composed in an attractive manner, so she did not stop watching after she found out it was anti-chemtrail: "His [the speaker's] voice makes you wanna listen to what he's saying, you know? Speaks slowly, and he articulates very well... [after watching the video], I became an avid skeptic." Furthermore, E5 mentioned that debunking videos facilitated his conversion to non-conspiratorial beliefs after he became skeptical about chemtrails.

Earlier, we discussed how some believers are hostile to online strangers who debunk their beliefs. When debunking evidence is from a community or people they care about, however, there is a chance for them to review their beliefs and change their mind due to social pressures and concerns. E2 was initially skeptical of chemtrails so he kept silent, but when he saw a photo of "chemtrail equipment" on a plane, he thought that he had found the solid proof and shared his belief on his Facebook timeline for the first time. However, one of his Facebook friends pointed out the fallacy in the narratives with a link to the evidence that the chemtrail equipment was "ballast barrels," a common equipment on the airplanes. This ex-believer described the embarrassment he felt after he checked the evidence: "Well I probably didn't want to believe him initially...knowing that I was shown that I had put up false information, it was embarrassment. Because I'm not trying to spread false information...I was like I got tricked" (E2). Along with a few other key points of reflection, he changed his beliefs about the legitimacy of the chemtrail conspiracy.

E3 and E1 told us that they were defensive about debunkers and debunking information online. However, they were ultimately persuaded by people they trust and care about. E3 mentioned his beliefs in chemtrails with one of his close friends, and his friend debunked the belief. He explained why he believed the words of his friend: "When it came to [my friend], it was different than those other people who are anti-chemtrails. Because [my friend] was somebody I knew personally for many years...he's a bit like a big brother." Similarly, E1 described how he was listening to his college professor in a class, and the professor debunked one of the conspiracy theories he believed, the New World Order. Even though E1 used to defend his beliefs against debunkers on the internet, he believed in the information shared by his professor: "I felt I had a good relationship with my professor, she was very educated and very engaging and also being respectful also helps." As we discussed earlier in 6.1, this combined with his change in religious beliefs became critical turning points for E1 to further abandon his beliefs in other conspiracy theories including chemtrails.

Ex-believers also explained that when the online debunkers communicated with friendliness and understanding, there was a chance for them to change their beliefs. After E5 became skeptical of chemtrails, he reached out to a debunker Facebook group. He reflected how the debunkers persuaded him this way:

"They wanna be as welcoming and as friendly as they can and actually answer all of the questions that people have to throw at them. Because they know that it's easy to believe in something like this, even for people that maybe are intelligent or well off. It's not just people with mental illnesses and crazy people that believe in these theories." (E5)

Through our interviews, we learned that anti-chemtrails activists deliberately created opportunities in online platforms for believers to expose their beliefs for the purpose of starting a conversation. When E4 was a believer, she entered an anti-chemtrail group by mistake. The group she joined had 
an identical name with a pro-chemtrail group she actually wished to join. When she requested to join, she was asked to answer several questions regarding her beliefs on chemtrails. After being admitted into the group, she was immediately tagged in a welcome post by a moderator, and the group members started a conversation with her to inquire and challenge her beliefs about chemtrails:

"[One debunker] listed out these bullet points of different things and he said I'll be glad to discuss any of them. So I read through the information, I did have some questions and he answered them factually...It made sense like I was saying, why would somebody spray their own family with harmful chemicals? How is it even possible?" (E4)

Having the many debunkers presenting debunking evidence at the same time was "a little bit overwhelming" for E4. However, she also appreciated the friendliness and approachability of some debunkers: "There were people willing to talk to me very very sensibly."

We have seen that the entertainment value of conspiracies can help believers dwell in these communities out of fun and curiosity. Yet, we heard from some ex-believers that when the entertainment value of the conspiracy community begins to wane, it can also affect one's beliefs in the conspiracy itself. For example, earlier we discussed how one individual (E7) said that he originally got into this conspiracy because of his curiosity, but then found entertainment and social value in his coordination efforts. This individual used to be a chemtrails activist, but became tired of his role. He described his frustration with the workload and how the work specifically became less entertaining and less fun. For this believer, his commitment to the conspiracy was strongly tied to his enjoyment of his role in the conspiracy community:

"Everybody was asking me questions about this [chemtrails]...it's a big vicious circle,and every day I'd receive literally dozens of emails, hundreds, and hundreds of messages with people asking questions...I think because it had started to be all-consuming, and it was affecting everything around me. My family life, my friends, everything else...I thought, 'Well, this is ridiculous. This is taking my life. Let's try, and see if this is fact...Well,hang on a minute. Let's do some research into why it happens."' (E7)

E7 then reached out to anti-chemtrails groups to learn debunking evidence, and ultimately stopped believing in chemtrails. His change of mind came after a decade of identifying as a believer.

\section{COLLECTIVE SENSEMAKING AND AMBIGUITY IN THE CHEMTRAIL CONSPIRACY}

One of the great promises of the internet is that it could democratize information access and provide the ability to explore massive amounts of information and share beliefs and experiences with others [59]. The rise of social media platforms explodes the magnitude of instant information sharing to a global scale. The velocity and range of online information sharing online has been credited with many positive social developments and outcomes, including civic involvement [67], providing better access to health information among youth [80], and connecting geographically dispersed families and friends [66].

However, the real and perceived scale of online social interaction can, "exacerbate the influence of the cognitive processes involved in the endorsement of conspiracy theories" [41]. The internet, for all its positive affordances, becomes far more than simply another channel for the diffusion of conspiracy theories. The internet presents a social context that facilitates the implicit endorsement of conspiracy theories [36]. As one of the believers in our study phrased it, finding so much perceived online support for the same conspiracy helps to affirm that, "I'm not the only one" (B2).

In our research, we find that the internet becomes one of the major sites for people's collective sensemaking about the ambiguous information of conspiracy theories. Conspiracy theories present 
a puzzle, with mysteries to solve in a sea of ambiguous information. However, the socio-technical context of the internet may inadvertently trap people in a perpetual state of ambiguity. Individuals may search in vain for a final unveiling of the "truth" about chemtrails. The social dynamics and technical affordances of online environments can reinforce a sense of abundance and collective agreement about pro-chemtrail information, and this perceived abundance of evidence then becomes the supporting validation of chemtrails.

\subsection{Ambiguity in the Chemtrail Conspiracy}

To make sense of conspiracy theories, individuals must wrestle with various sources of ambiguity. According to McCaskey, ambiguous situations are characterized by phenomena such as multiple and conflicting interpretations, unreliable information, and reliance on personal values to make sense of a situation [51]. There are multiple conspiracy theories about chemtrails, and they each raise different ambiguities. In the theories participants share with us, there are often missing components: who are the conspirators, what is the true purpose of chemtrails, what are the specific chemicals, and so on. Believers constantly make decisions about whether to believe the informational cues they watch, hear, or read on the internet.

Weick argues that ambiguity in sensemaking indicates that "the assumptions necessary for rational decision making are not met" [89]. Weick believes that people tend to turn ambiguous sensemaking into a collective, social process. It involves issues that "need to be hammered out through subjective opinions, because no one has the foggiest idea what objective data, if any, are relevant" [89]. In our research, we find that the internet becomes one of the major sites for people's collective sensemaking about ambiguity.

\subsection{Collective Sensemaking and a False Sense of Information Diversity}

We find that believers think that they are exposed to large amounts of supporting information from reliable sources on the internet. However, our interviews reveal online environments that are far less homogenous and unified than some believers may first realize. People's past beliefs and worldviews, technological affordances as well as the social process can collectively create a false sense of information abundance and thriving community.

Whether intentional or not, recommendation algorithms and subscription mechanisms concentrate pro-conspiracy information for believers at the expense of balanced discourse. With the convenience to easily share information, along with believers' dedication to filter pro-conspiracy cues and advocate their beliefs, the same uncorroborated piece of information may appear substantiated and meaningful as it appears all across the internet. Additionally, there is often no direct supporting evidence of chemtrails in this collective sensemaking process. As a result, respondents indicate that they use a wide range of information to reduce ambiguity and to better align with their existing frames. For example, believers expressed the importance of informational cues including news on strange weather such as tornadoes, alignments with other conspiracy theories, and negative news about the government.

Our research also shows that some believers hope to find social belonging or get some entertainment value from their participation in conspiracy communities, even if they do not necessarily believe different aspects of the conspiracy. Such findings suggest that the magnitude of the active believer community may actually be far less than what people see when they first participate or join these online forums and groups. However, this false sense of collective participation may lead even more people to become aware or interested in the conspiracy. In this way, online conspiracy communities can become self-reinforcing: people participate because it is mostly entertaining or fun, yet the presence of an active community lends credence to the belief that there must be something important going on. 


\subsection{Trapped in Ambiguity}

As with most complex and ambiguous problems, an abundance of information does not necessarily equal more knowledge or truth. As Weick argues, "the problem in ambiguity is not that the real world is imperfectly understood and that more information will remedy that. The problem is that information may not resolve misunderstandings" [89]. With the abundance of information sharing in online conspiracy communities, believers told us that they still find it hard to make sense of what leads to the long-lasting condensation trails in the sky. As we saw throughout our interviews, many believers become frustrated by the fact that a final unveiling and proof of the "truth" behind chemtrails never seems to occur.

There is psychological evidence that conspiracy beliefs do not really fulfill people's initial desire to find factual "truth" - conspiracies are more appealing than satisfying [18]. However, many believers still gain much from the group sensemaking process when it can fulfill purposes other than finding clarity in the presence of ambiguity, or solving other problems in life. For those believers, their main concern may not be to strengthen sensemaking with more accurate, factual evidence. Instead, they take the conspiracy theory as a medium to socially express their dissatisfaction with reality, find a sense of community with like-minded others, and perhaps even find some welcome entertainment along the way.

Even if some believers are convinced that the evidence they acquire is sufficient for drawing out a consistent theory of chemtrails, there may not be enough details or concrete forms of evidence to grant actions to take. For example, some believers may think chemtrails caused their health problems or that depopulation is happening in their communities. Yet, they may become trapped in the conspiracy sensemaking and advocacy process, unable to directly address their core problems. Melley describes a core fear among conspiracy believers as "agency panic," which is the anxiety about a loss of autonomy or self-control to powerful authorities [53]. As we learned from our respondents, many chemtrail believers are motivated by regaining control: they have genuine concerns about authority, science, the environment, health and a range of other important issues. However, believers do not have the chance to effect change in chemtrails, beyond collecting and sharing information on or off the internet.

\section{THE SOCIO-TECHNICAL PROBLEM OF EXITING CONSPIRACY BELIEFS}

How do conspiracy believers change their minds and stop believing in conspiracy theories? Our research demonstrates the process of exiting belief among seven ex-believers. Though they follow different paths, a key similarity in their belief-changing process is the exposure to counter-narratives that made a significant impact on their beliefs. However, the contexts in which these individuals learned about counter-narratives were different in important ways that we detail below.

Current research on debunking false conspiracy theories and misinformation emphasizes the importance of exposure to counter-narratives. As discussed earlier in this paper, there are many different techniques for online fact-checking, which is often about assigning "truth" to online claims along with relevant data and documents from verified, corroborated, or credible sources $[12,86,92]$. To date, there are significant (and growing) numbers of fact-checking websites on the internet [32]. Sometimes online platforms get involved in fact-checking by deploying mechanisms to establish truthfulness [22, 50]. In other cases, individual users directly provide counter-evidence when interacting with other users, or help platforms identify problematic content [22].

Although debunking information cues are essential in changing conspiracy believers' beliefs, our findings suggest that it doesn't work alone in order to be effective. Through examining our first and second research question on how beliefs, worldviews, social interaction and technical 
affordances influence the sensemaking process, we find that fact-checking can be challenged or completely negated by the reinforcing force of these factors.

As discussed above, believers tend to locate in echo chambers where pro-conspiracy information is concentrated and debunking information is eliminated. Research also shows that debunking evidence primarily circulates in "pro-science" instead of "pro-conspiracy" communities [6]. Even when our interviewees are aware of some debunking information, they indicate that they adopt the chemtrail conspiracy because of the sheer amount of pro-conspiracy information that they perceive compared to anti-conspiracy information. As a result, the views and counter-evidence of debunkers might not be convincing in the presence of overwhelming amounts of pro-conspiracy information and narratives. While some individual debunkers try to locate and talk with believers, our research shows that some believers choose to stay silent about their beliefs outside the conspiracy communities in order to avoid conversations with non-believers.

Our interviews also show how believers' frames may lead them to dismiss fact-checking information without close interpretation. In experimental settings, researchers often examine the effectiveness of fact-checking after participants fully read and interpret it [3, 32, 35]. However, our research shows that believers may quickly dismiss fact-checking information on social media as soon as they recognize the information is anti-chemtrails. Furthermore, some believers told us that they think such information comes from "shills," who are the government agents who try to cover up the conspiracy theory, which turns the debunking information into evidence in support of conspiracy theories. This admission by our interviewees is consistent with the predictions of cognitive dissonance, where individuals dismiss, downplay, or ignore counter-evidence as a way to reduce the cognitive strain of inconsistent information [25].

\subsection{Changing Beliefs: Insights from Ex-believers}

Many conspiracy theories, including the chemtrail conspiracy in the present study, involve significant amounts of misinformation and uncorroborated evidence that is not consistent with science. If presenting counter-evidence alone is not effective at challenging misinformation, how can believers reconsider (or even change) their beliefs? Given the responses of ex-believers, we suggest that the context in which counter-evidence is conveyed plays an especially important role in the sensemaking process.

In the process of exiting beliefs, we found that several believers were primarily persuaded by people they trust, or with whom they already have close relationships. For example, E1 trusted and respected his college professor, and E2 was convinced by his close friend. In the online world, debunkers can also work to build trust and show friendliness to believers, which was a critical part of the belief-changing process for two ex-believers in our study (E4, E5).

Additionally, some ex-believers (e.g., E6 and E4) explained how their changes in belief relied on deception. Both ex-believers were tricked into watching a debunking video or joining a Facebook group thinking they were supportive of their existing beliefs when they were not. In particular, E6 explained that she used to dismiss counter-evidence directly. With her guard down, not realizing she was watching an anti-conspiracy video, she reported feeling more open-minded to the counternarratives. The unexpectedness of confronting one's beliefs can be more effective, as the believer is not primed to dismiss or ignore counter-evidence.

We want to note that though the ex-believers in our study were able to get exposure to and make sense of counter-narratives, these opportunities appear somewhat exceptional. First, we cannot be sure when an algorithm will recommend a debunking video to a believer, or when the believers will enter a debunker Facebook group and confront conflicting evidence for the first time. In fact, nearly all of the ex-believers in our study said that they usually do not come across counter-narratives unless they actively search by themselves. 


\section{IMPLICATIONS}

Overall, a key takeaway is that combating false conspiracies and other forms of misinformation online requires concerted efforts to increase exposure to truthful counter-narratives using both social (i.e., encouraging productive discussions and debates among trustworthy individuals), and technological considerations (i.e., reducing opacity in algorithmic recommendations). It is essential that we consider all of these social and technical factors holistically if we hope to address this challenging socio-technical problem.

It is well understood that internet can be a host to echo chambers, where individuals form niche communities where they only search for, share, or consume information that reinforces pre-existing beliefs [65]. The break from pro-conspiracy echo chambers may require purposeful efforts to allow silent believers to reveal beliefs, or recommendation algorithms to suggest anti-conspiracy videos Addressing believers' defensiveness may require building trust and understanding with debunkers, or being "surprised" by counter-evidence they thought was pro-conspiracy.

One fruitful approach to productively challenge beliefs may be to build understanding and trust before conveying counter-evidence. While this is no small challenge, a growing body of social psychological research shows that people are more likely to be convinced to change their mind (e.g., from denying climate change to believing in it) if an appeal is made to the deniers' own values, such as framing pro-environmental change as patriotic [26] or positioning a political disagreement in terms of one's moral values [24]. There is ample opportunity to help people find and employ these common values in online communities.

Another important way to address the reinforcement of conspiracy theories in online communities is to actively work to enhance the social translucence of the online platforms that host these interactions. As Erickson and Kellogg argue, the key characteristics of socially translucent systems are visibility, awareness, and accountability [21]. Our findings show that believers often have little awareness about the existence of their own echo chambers within online conspiracy groups. Many socially translucent systems primarily focus on the visibility of online social relationships, such as visualizing social networks and online social groups. Additionally, McDonald, Gokham and Zachry explain that we should also make visible the informational processes and interpretations of online systems (e.g., algorithms) [52]. As such, the development and implementation of socially translucent systems is a socio-technical solution to the socio-technical problem of information ambiguity and the proliferation of conspiracy theories online. The continuing call among CSCW researchers and designers for more socially translucent online platforms and systems is consistent and robust $[20,30]$. We believe that any concerted effort to tackle the proliferation of unsubstantiated conspiracies online must include socially translucent systems that help us become more directly informed about the social relationships and technologies that we use to inform ourselves.

\section{CONCLUSION}

We should expect lots of variability in beliefs and worldviews in our social world, whether online or offline. In a diverse society of ideas and opinions, it is normal (and even healthy) to expect narratives about conspiracy theories to emerge from time to time. In fact, some conspiracies turn out to be true, like the Watergate Scandal in American politics [74] or the idea that the water is not safe to drink on some American cities like Flint, Michigan [8]. What is critically important is that we have a fair way to assess where the information comes from, and whether it is credible or not.

In our research, we use Weick's sensemaking framework to analyze how people's beliefs and worldviews and the socio-technical context of the internet may collectively affect how they interpret online information about conspiracy theories. Through understanding the sensemaking process 
of believers and ex-believers, we see how those factors play important roles in both entering and exiting belief processes.

The study of conspiracy theories is important for understanding the broader issues of misinformation and disinformation online. Conspiracy theories create polarizations on the internet between the science and conspiracy communities [6], and debunking false (and potentially dangerous) conspiracy theories is an important issue for any functioning society. Just as some friendly debunkers were able to build connections with believers, addressing the issues of false conspiracy theories may require us to see our similarities and common concerns instead of focusing solely on our differences in belief. This challenge also requires us to see the problem from a socio-technical perspective by treating the technologies and the social relationships on the internet together as an organic whole. We hope our research contribute to the understanding of conspiracy believers and their belief changing process, and shed light on how we may better facilitate people in making sense of online information.

\section{ACKNOWLEDGMENTS}

We thank our interviewees for their participation in our study. We especially want to thank our anonymous reviewers and the members of the 2020 Berkeley I School Doctoral Research and Theory Workshop for their insights and suggestions on previous versions of this work.

\section{REFERENCES}

[1] Gordon W Allport. 1985. The historical background of social psychology. The handbook of social psychology (1985).

[2] Amarnath Amarasingam and Marc-André Argentino. 2020. The QAnon conspiracy theory: A security threat in the making. CTC Sentinel 13, 7 (2020), 37-44.

[3] Michelle A Amazeen, Emily Thorson, Ashley Muddiman, and Lucas Graves. 2018. Correcting political and consumer misperceptions: The effectiveness and effects of rating scale versus contextual correction formats. Fournalism \& Mass Communication Quarterly 95, 1 (2018), 28-48.

[4] Michael Barkun. 2013. A culture of conspiracy: Apocalyptic visions in contemporary America. Vol. 15. Univ of California Press.

[5] Jamie Bartlett and Carl Miller. 2010. The power of unreason: Conspiracy theories, extremism and counter-terrorism. Demos London.

[6] Alessandro Bessi, Mauro Coletto, George Alexandru Davidescu, Antonio Scala, Guido Caldarelli, and Walter Quattrociocchi. 2015. Science vs conspiracy: Collective narratives in the age of misinformation. PloS one 10, 2 (2015).

[7] Kirsten R Butcher and Tamara Sumner. 2011. Self-directed learning and the sensemaking paradox. Human-Computer Interaction 26, 1-2 (2011), 123-159.

[8] Lindsey J. Butler, Madeleine K. Scammell, and Eugene B. Benson. 2016. The Flint, Michigan, Water Crisis: A Case Study in Regulatory Failure and Environmental Injustice. Environmental fustice 9, 4 (Aug. 2016), 93-97. https: //doi.org/10.1089/env.2016.0014

[9] Rose Cairns. 2016. Climates of suspicion: 'Chemtrail' conspiracy narratives and the international politics of geoengineering. Geographical fournal 182, 1 (2016), 70-84. https://doi.org/10.1111/geoj.12116

[10] John M Carey, Brendan Nyhan, Benjamin Valentino, and Mingnan Liu. 2016. An inflated view of the facts? How preferences and predispositions shape conspiracy beliefs about the Deflategate scandal. Research \& Politics 3, 3 (2016), 2053168016668671.

[11] Nick Chater and George Loewenstein. 2016. The under-appreciated drive for sense-making. fournal of Economic Behavior \& Organization 126 (2016), 137-154.

[12] Katherine Clayton, Spencer Blair, Jonathan A Busam, Samuel Forstner, John Glance, Guy Green, Anna Kawata, Akhila Kovvuri, Jonathan Martin, Evan Morgan, et al. 2020. Real solutions for fake news? Measuring the effectiveness of general warnings and fact-check tags in reducing belief in false stories on social media. Political Behavior 42, 4 (2020) 1073-1095.

[13] Manuel J Cobo, Antonio Gabriel López-Herrera, Enrique Herrera-Viedma, and Francisco Herrera. 2011. Science mapping software tools: Review, analysis, and cooperative study among tools. Fournal of the American Society for information Science and Technology 62, 7 (2011), 1382-1402.

[14] Geoffrey L. Cohen, Joshua Aronson, and Claude M. Steele. 2000. When Beliefs Yield to Evidence: Reducing Biased Evaluation by Affirming the Self. Personality and Social Psychology Bulletin 26, 9 (Nov. 2000), 1151-1164. https: 
//doi.org/10.1177/01461672002611011

[15] Morris B Cohen, M Gołkowski, and Umran S Inan. 2008. Orientation of the HAARP ELF ionospheric dipole and the auroral electrojet. Geophysical research letters 35, 2 (2008).

[16] Matthew Costello, James Hawdon, Thomas Ratliff, and Tyler Grantham. 2016. Who views online extremism? Individual attributes leading to exposure. Computers in Human Behavior 63 (Oct. 2016), 311-320. https://doi.org/10.1016/j.chb. 2016.05.033

[17] Michela Del Vicario, Gianna Vivaldo, Alessandro Bessi, Fabiana Zollo, Antonio Scala, Guido Caldarelli, and Walter Quattrociocchi. 2016. Echo chambers: Emotional contagion and group polarization on facebook. Scientific reports 6 (2016), 37825.

[18] Karen M. Douglas, Robbie M. Sutton, and Aleksandra Cichocka. 2017. The psychology of conspiracy theories. Current Directions in Psychological Science 26, 6 (2017), 538-542. https://doi.org/10.1177/0963721417718261

[19] Owen Dyer. 2020. Trump claims public health warnings on covid-19 are a conspiracy against him. bmj 368 (2020), $\mathrm{m} 941$.

[20] Upol Ehsan, Q Vera Liao, Michael Muller, Mark O Riedl, and Justin D Weisz. 2021. Expanding explainability: Towards social transparency in ai systems. In Proceedings of the 2021 CHI Conference on Human Factors in Computing Systems. $1-19$.

[21] Thomas Erickson and Wendy A Kellogg. 2000. Social translucence: an approach to designing systems that support social processes. ACM transactions on computer-human interaction (TOCHI) 7, 1 (2000), 59-83.

[22] Facebook. 2020. How Our Fact-Checking Program Works. https://www.facebook.com/journalismproject/programs/ third-party-fact-checking/how-it-works

[23] Justin Farrell, Kathryn McConnell, and Robert Brulle. 2019. Evidence-based strategies to combat scientific misinformation. Nature Climate Change 9, 3 (March 2019), 191-195. https://doi.org/10.1038/s41558-018-0368-6

[24] Matthew Feinberg and Robb Willer. 2019. Moral reframing: A technique for effective and persuasive communication across political divides. Social and Personality Psychology Compass 13, 12 (2019), e12501.

[25] Leon Festinger. 1962. A theory of cognitive dissonance. Vol. 2. Stanford university press.

[26] Irina Feygina, John T Jost, and Rachel E Goldsmith. 2010. System justification, the denial of global warming, and the possibility of "system-sanctioned change". Personality and social psychology bulletin 36, 3 (2010), 326-338.

[27] Marc Fisher, John Woodrow Cox, and Peter Hermann. 2016. Pizzagate: From rumor, to hashtag, to gunfire in DC. Washington Post 6 (2016).

[28] D J Flynn, Brendan Nyhan, and Jason Reifler. 2017. The nature and origins of misperceptions: Understanding false and unsupported beliefs about politics. Political Psychology 38 (2017), 127-150.

[29] Christine Garwood. 2008. Flat earth: the history of an infamous idea. Pan Macmillan.

[30] Sucheta Ghoshal and Amy Bruckman. 2019. The role of social computing technologies in grassroots movement building. ACM Transactions on Computer-Human Interaction (TOCHI) 26, 3 (2019), 1-36.

[31] Erving Goffman. 1974. Frame analysis: An essay on the organization of experience. Harvard University Press.

[32] Naeemul Hassan, Gensheng Zhang, Fatma Arslan, Josue Caraballo, Damian Jimenez, Siddhant Gawsane, Shohedul Hasan, Minumol Joseph, Aaditya Kulkarni, Anil Kumar Nayak, et al. 2017. Claimbuster: The first-ever end-to-end fact-checking system. Proceedings of the VLDB Endowment 10, 12 (2017), 1945-1948.

[33] Uri Hasson, Joseph P Simmons, and Alexander Todorov. 2005. Believe it or not: On the possibility of suspending belief. Psychological science 16, 7 (2005), 566-571.

[34] Kyle Ingle, Stacey Rutledge, and Jennifer Bishop. 2011. Context matters: principals' sensemaking of teacher hiring and on-the-job performance. Fournal of Educational Administration (2011).

[35] Shan Jiang and Christo Wilson. 2018. Linguistic signals under misinformation and fact-checking: Evidence from user comments on social media. Proceedings of the ACM on Human-Computer Interaction 2, CSCW (2018), 1-23.

[36] Pamela J Kalbfleisch. 2003. Credibility for the 21st century: Integrating perspectives on source, message, and media credibility in the contemporary media environment. In Communication yearbook 27. Routledge, 307-350.

[37] David W Keith. 2000. Geoengineering the climate: History and prospect. Annual review of energy and the environment 25, 1 (2000), 245-284. Publisher: Annual Reviews 4139 El Camino Way, PO Box 10139, Palo Alto, CA 94303-0139, USA

[38] G Klein. 1989. Recognition-primed decisions. (1989).

[39] Gary Klein, Jennifer K Phillips, Erica L Rall, and Deborah A Peluso. 2007. A data-frame theory of sensemaking. In Expertise out of context: Proceedings of the sixth international conference on naturalistic decision making. New York, NY: Lawrence Erlbaum Assoc Inc, 113-155.

[40] Gary A Klein, Roberta Calderwood, and Anne Clinton-Cirocco. 1986. Rapid decision making on the fire ground. In Proceedings of the human factors society annual meeting, Vol. 30. Sage Publications Sage CA: Los Angeles, CA, 576-580.

[41] Olivier Klein, Nicolas Van der Linden, Myrto Pantazi, and Mikhail Kissine. 2015. Behind the screen conspirators: Paranoid social cognition in an online age. (2015). 
[42] Peter Knight. 2008. Outrageous Conspiracy Theories: Popular and Official Responses to 9/11 in Germany and the United States. New German Critique 35, 1 (2008), 165-193. https://doi.org/10.1215/0094033x-2007-024

[43] Justin Kosslyn and Cong Yu. 2017. Fact Check now available in Google Search and News around the world. Google (April 2017). https://www.blog.google/products/search/fact-check-now-available-google-search-and-news-around-world/

[44] Yubo Kou, Xinning Gui, Yunan Chen, and Kathleen Pine. 2017. Conspiracy talk on social media: collective sensemaking during a public health crisis. Proceedings of the ACM on Human-Computer Interaction 1, CSCW (2017), 61-61.

[45] PM Krafft and Joan Donovan. 2020. Disinformation by design: The use of evidence collages and platform filtering in a media manipulation campaign. Political Communication 37, 2 (2020), 194-214.

[46] Arie W Kruglanski, Michele J Gelfand, Jocelyn J Bélanger, Anna Sheveland, Malkanthi Hetiarachchi, and Rohan Gunaratna. 2014. The psychology of radicalization and deradicalization: How significance quest impacts violent extremism. Political Psychology 35 (2014), 69-93. Publisher: Wiley Online Library.

[47] George Lakoff. 2008. Women, fire, and dangerous things. University of Chicago press.

[48] Bruno Latour and Steve Woolgar. 2013. Laboratory life: The construction of scientific facts. Princeton University Press.

[49] Stephan Lewandowsky, Ullrich K H Ecker, Colleen M Seifert, Norbert Schwarz, and John Cook. 2012. Misinformation and its correction: Continued influence and successful debiasing. Psychological Science in the Public Interest 13, 3 (2012), 106-131.

[50] Louise Matsakis. 2018. YouTube Will Link Directly to Wikipedia to Fight Conspiracy Theories. Wired (2018) https://www.wired.com/story/youtube-will-link-directly-to-wikipedia-to-fight-conspiracies/

[51] Michael B McCaskey. 1982. The executive challenge: Managing change and ambiguity. Marshfield, Mass.: Pitman.

[52] David W McDonald, Stephanie Gokhman, and Mark Zachry. 2012. Building for social translucence: a domain analysis and prototype system. In Proceedings of the ACM 2012 conference on computer supported cooperative work. 637-646.

[53] Timothy Melley. 2000. Empire of conspiracy: The culture of paranoia in postwar America. Cornell University Press.

[54] Sharan B Merriam and Robin S Grenier. 2019. Qualitative research in practice: Examples for discussion and analysis. Jossey-Bass.

[55] Amy Mitchell, Mark Jurkowitz, J Baxter Oliphant, and Elisa Shearer. 2020. Three months in, many Americans see exaggeration, conspiracy theories and partisanship in COVID-19 news. Pew Research Center (2020).

[56] Tanushree Mitra, Scott Counts, and James W Pennebaker. 2016. Understanding Anti-Vaccination Attitudes in Social Media. In Proceedings of the Tenth International AAAI Conference on Web and Social Media - ICWSM '16. 269-278. https://doi.org/10.1111/aec.12581

[57] Brendan Nyhan and Jason Reifler. 2010. When corrections fail: The persistence of political misperceptions. Political Behavior 32, 2 (June 2010), 303-330. https://doi.org/10.1007/s11109-010-9112-2

[58] Joyce S Osland and Allan Bird. 2000. Beyond sophisticated stereotyping: Cultural sensemaking in context. Academy of Management Perspectives 14, 1 (2000), 65-77.

[59] Zizi Papacharissi. 2002. The virtual sphere: The internet as a public sphere. New media \& society 4, 1 (2002), 9-27.

[60] Sharoda A Paul and Meredith Ringel Morris. 2009. CoSense: enhancing sensemaking for collaborative web search. In Proceedings of the SIGCHI conference on human factors in computing systems. 1771-1780.

[61] Shruti Phadke, Mattia Samory, and Tanushree Mitra. 2021. What Makes People Join Conspiracy Communities? Role of Social Factors in Conspiracy Engagement. Proceedings of the ACM on Human-Computer Interaction 4, CSCW3 (2021), 1-30.

[62] Peter Pirolli and Stuart Card. 2005. The sensemaking process and leverage points for analyst technology as identified through cognitive task analysis. In Proceedings of international conference on intelligence analysis, Vol. 5. McLean, VA, USA, 2-4.

[63] Peter Pirolli and Daniel M Russell. 2011. Introduction to this special issue on sensemaking.

[64] Gregory A. Poland and Robert M. Jacobson. 2001. Understanding those who do not understand: A brief review of the anti-vaccine movement. In Vaccine, Vol. 19. Elsevier, 2440-2445. https://doi.org/10.1016/S0264-410X(00)00469-2

[65] Walter Quattrociocchi, Antonio Scala, and Cass R. Sunstein. 2016. Echo Chambers on Facebook. SSRN (June 2016). https://doi.org/10.2139/ssrn.2795110

[66] Harrison Rainie and Barry Wellman. 2012. Networked: The new social operating system. Vol. 419. Mit Press Cambridge, MA.

[67] Ronald E Rice. 2002. Primary issues in Internet use: Access, civic and community involvement, and social interaction and expression. Handbook of new media: Social shaping and consequences of ICTs (2002), 105-129.

[68] Peter Smith Ring and Gordon P Rands. 1989. Sensemaking, understanding, and committing: Emergent interpersonal transaction processes in the evolution of 3M's microgravity research program. Research on the management of innovation: The Minnesota studies (1989), 337-366.

[69] Sarah T Roberts. 2019. Behind the screen. Yale University Press.

[70] Oliver C Robinson. 2014. Sampling in interview-based qualitative research: A theoretical and practical guide. Qualitative research in psychology 11, 1 (2014), 25-41. 
[71] Johnny Saldaña. 2021. The coding manual for qualitative researchers. sage.

[72] Mattia Samory and Tanushree Mitra. 2018. Conspiracies online: User discussions in a conspiracy community following dramatic events. In Proceedings of the International AAAI Conference on Web and Social Media, Vol. 12.

[73] Mattia Samory and Tanushree Mitra. 2018. 'The Government Spies Using Our Webcams' The Language of Conspiracy Theories in Online Discussions. Proceedings of the ACM on Human-Computer Interaction 2, CSCW (2018), 1-24.

[74] Michael Schudson. 2004. Notes on Scandal and the Watergate Legacy. American Behavioral Scientist 47, 9 (May 2004), 1231-1238. https://doi.org/10.1177/0002764203262345

[75] Irving Seidman. 2006. Interviewing as qualitative research: A guide for researchers in education and the social sciences. Teachers college press.

[76] Ashley Shelby and Karen Ernst. 2013. Story and science. Human Vaccines \& Immunotherapeutics 9, 8 (Aug. 2013), 1795-1801. https://doi.org/10.4161/hv.24828

[77] Margaret T Singer. 1979. Coming out of the cults. Psychology today 12, 8 (1979), 72-82.

[78] Kate Starbird. 2017. Examining the alternative media ecosystem through the production of alternative narratives of mass shooting events on Twitter. In Proceedings of the International AAAI Conference on Web and Social Media, Vol. 11.

[79] Kate Starbird, Jim Maddock, Mania Orand, Peg Achterman, and Robert M Mason. 2014. Rumors, false flags, and digital vigilantes: Misinformation on twitter after the 2013 boston marathon bombing. IConference 2014 Proceedings (2014).

[80] Mary Summer Starling, Coye Cheshire, Julianna Deardorff, and Amani Nuru-Jeter. 2018. Late Adolescent User Experiences with Online Sexual Health Resources: A Qualitative Study. American fournal of Sexuality Education 13, 4 (2018), 487-503.

[81] Cass R Sunstein. 2018. \# Republic: Divided democracy in the age of social media. Princeton University Press.

[82] Cass R Sunstein and Adrian Vermeule. 2009. Conspiracy theories: Causes and cures. Fournal of Political Philosophy 17, 2 (2009), 202-227.

[83] Dustin Tingley and Gernot Wagner. 2017. Solar geoengineering and the chemtrails conspiracy on social media. Palgrave Communications 3, 1 (Dec. 2017), 12-12. https://doi.org/10.1057/s41599-017-0014-3 Publisher: Nature Publishing Group.

[84] Joseph E. Uscinski and Joseph M. Parent. 2014. American conspiracy theories. Oxford University Press.

[85] Jan-Willem Van Prooijen, André PM Krouwel, and Thomas V Pollet. 2015. Political extremism predicts belief in conspiracy theories. Social Psychological and Personality Science 6, 5 (2015), 570-578.

[86] Andreas Vlachos and Sebastian Riedel. 2014. Fact checking: Task definition and dataset construction. In Proceedings of the ACL 2014 workshop on language technologies and computational social science. 18-22.

[87] Nathan Walter, Jonathan Cohen, R Lance Holbert, and Yasmin Morag. 2020. Fact-checking: A meta-analysis of what works and for whom. Political Communication 37, 3 (2020), 350-375.

[88] Robert H Waterman. 1993. Adhocracy. WW Norton \& Company.

[89] Karl E Weick. 1995. Sensemaking in organizations. Vol. 3. Sage.

[90] Stuart A. Wright. 1987. Leaving cults: The dynamics of defection. Society for the Scientific Study of Religion, Storrs, CT, US.

[91] Lixiu Yu, Aniket Kittur, and Robert E Kraut. 2014. Distributed analogical idea generation: inventing with crowds. In Proceedings of the SIGCHI conference on Human Factors in Computing Systems. 1245-1254.

[92] Amy X Zhang, Aditya Ranganathan, Sarah Emlen Metz, Scott Appling, Connie Moon Sehat, Norman Gilmore, Nick B Adams, Emmanuel Vincent, Jennifer Lee, Martin Robbins, et al. 2018. A structured response to misinformation: Defining and annotating credibility indicators in news articles. In Companion Proceedings of the The Web Conference 2018. 603-612.

Received April 2021; revised July 2021; accepted July 2021 